\title{
GEOMETRIC MISMATCH OF THE AORTIC AND PULMONARY ROOTS CAUSES AORTIC INSUFFICIENCY AFTER THE ROSS PROCEDURE
}

Tirone E. David, MD

Ahmed Omran, MD

Gary Webb, MD

Harry Rakowski, MD

Susan Armstrong, Msc

Zhao Sun, PhD
Background: Geometric mismatch between the two semilunar valves can cause aortic insufficiency after the Ross procedure. Thus, whenever the aortic root is larger than the pulmonary root, surgical reduction of the aortic anulus or of the sinotubular junction (or both) to match the diameters of the pulmonary root is necessary to prevent late malfunction of the pulmonary autograft. Methods: The Ross procedure was performed in 81 patients during the past 5 years. The diameters of the aortic and pulmonary roots were measured in 77 patients. Reduction of the aortic anulus and of the sinotubular junction was necessary in 27 patients, reduction of the aortic anulus alone in 12 , and reduction of the sinotubular junction alone in 10. The pulmonary autograft was implanted in the subcoronary position in the aortic root in two patients, as a complete root replacement in 58 , and as an inclusion root in 21. Results: There was one operative death, caused by myocardial infarction. Aortic insufficiency developed in one patient who did not have measurement and reduction of the aortic anulus, and aortic root replacement was necessary 2 weeks later. Patients have been followed up from 2 to 64 months (mean 15 months). Two patients have required late reoperations: one because of pulmonary artery stenosis and the other because of a false aneurysm between the autograft and the mitral valve. The most recent Doppler echocardiographic study shows that $90 \%$ of the patients have only trace or no aortic insufficiency, and $10 \%$ have mild aortic insufficiency. Conclusion: This experience suggests that adjustment of the diameter of the aortic anulus or of the sinotubular junction of the aorta may be important to prevent aortic insufficiency after the Ross procedure. (J Thorac Cardiovasc Surg 1996;112:1231-9)
T he Ross procedure is a complex operation whereby the patient's diseased aortic valve is replaced with the normal pulmonary valve. ${ }^{1}$ Regardless of the operative technique used to implant the pulmonary valve in the aortic position, postoperative aortic insufficiency is common and its severity increases with time in a number of patients. ${ }^{2-7}$ The

From the Divisions of Cardiovascular Surgery and Cardiology of The Toronto Hospital and The University of Toronto, Toronto, Ontario, Canada.

Read at the Seventy-sixth Annual Meeting of The American Association for Thoracic Surgery, San Diego, Calif., April 28-May 1, 1996.

Received for publication April 24, 1996; revisions requested June 11, 1996; revisions received July 8, 1996; accepted for publication July 15, 1996.

Address for reprints: T. E. David, MD, 200 Elizabeth St.13EN219, Toronto, Ontario, Canada M5G $2 \mathrm{C} 4$.

Copyright (C) 1996 by Mosby-Year Book, Inc.

$0022-5223 / 96 \$ 5.00+0 \quad \mathbf{1 2 / 6 / 7 6 5 4 7}$ resulting aortic insufficiency may jeopardize the long-term results of so complex an operation. ${ }^{2,3} \mathrm{We}$ believe that geometric mismatch between the diseased aortic valve and the normal pulmonary valve is a common cause of aortic insufficiency after this operation. Therefore aortic insufficiency may be prevented by adjusting the diameter of the aortic anulus and of the sinotubular junction of the aortic root to those of the pulmonary root during implantation of the pulmonary valve in the aortic position.

Anatomic features of the normal semilunar valves

The two semilunar valves have a common embryologic origin, the truncus arteriosus. The aortic and pulmonary roots have similar anatomic features. Both of them have three sinuses and three leaflets. There is a fairly constant relationship between the size of a sinus and its leaflet. In the aortic root, the noncoronary sinus and its leaflet is larger than the right and left sinuses and their leaflets. ${ }^{8-10}$ In the 


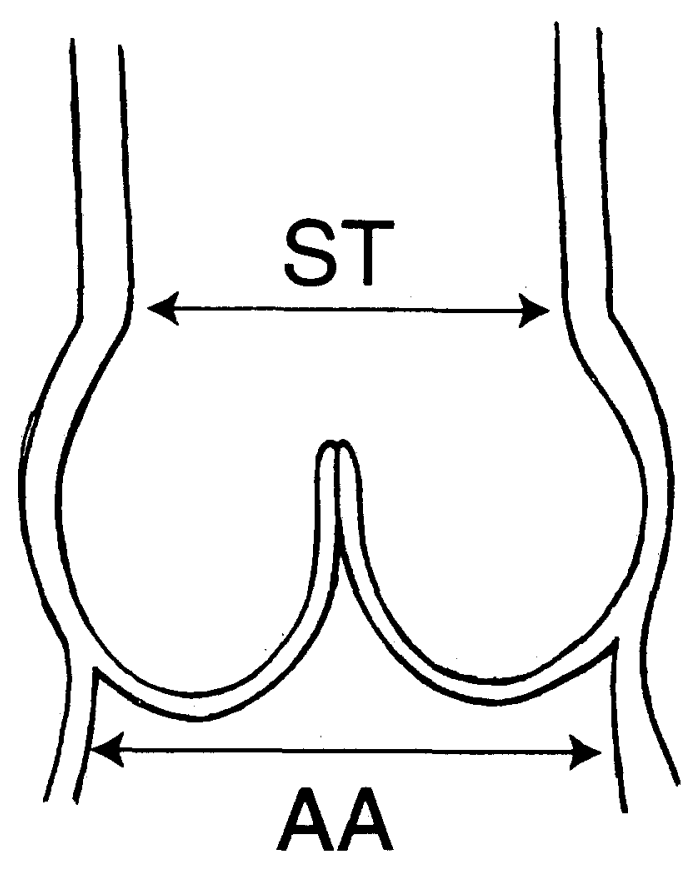

Fig. 1. Semilunar valve. The diameter of the valve anulus (AA) is $10 \%$ to $15 \%$ larger than the diameter of the sinotubular junction $(S T)$.

pulmonary root, the anterior and right sinuses and their leaflets are minimally larger than the left sinus and its leaflet. The leaflets of the semilunar valves are attached to the arterioventricular junction along a crescentic line that is surgically referred to as valve anulus. Approximately $45 \%$ of the circumference of the aortic root is attached to left ventricular muscle (interventricular septum) and $55 \%$ to fibrous tissue. ${ }^{8}$ The pulmonary root is attached solely to right ventricular muscle (conus arteriosus). The pulmonary anulus is distensible because it is attached to rather thin ventricular muscle. The distal end of the sinuses of the semilunar valves is demarcated by a ridge, called the sinotubular junction. The upper part of the commissures is immediately below the sinotubular junction. There is a fairly constant relationship between the diameter of the sinotubular junction and the diameter of the aortic anulus. ${ }^{8-10}$ The diameter of the aortic anulus is $10 \%$ to $15 \%$ larger than the diameter of the sinotubular junction, ${ }^{10}$ as illustrated in Fig. 1. Although the pulmonary anulus is more distensible than the aortic anulus, we assume that these geometric relationships are also valid for the pulmonary valve.

Provided that the leaflets are normal, aortic valve competence depends on the sinotubular junction
Table I. Clinical, echocardiographic, and pathologic data

\begin{tabular}{lc}
\hline New York Heart Association & \\
Class I & $13(16)$ \\
Class II & $52(64)$ \\
Class III & $12(15)$ \\
Class IV & $4(5)$ \\
Aortic valve lesion & \\
Stenosis & $42(52)$ \\
Insufficiency & $29(36)$ \\
Mixed & $10(12)$ \\
Left ventricular ejection fraction & \\
$>54 \%$ & $43(53)$ \\
$40 \%$ to $54 \%$ & $33(41)$ \\
$21 \%$ to $39 \%$ & $5(6)$ \\
$<21 \%$ & 0 \\
Valve pathology & \\
Biscuspid & $53(65)$ \\
Other congenital & $21(26)$ \\
Rheumatic & $1(1)$ \\
Prosthetic & $6(7)$ \\
\hline
\end{tabular}

Percentages are shown in parenthesis.

and valve anulus. ${ }^{11,12}$ Thus, if the sinotubular junction dilates, the commissures are pulled outward and prevent the leaflets from coapting centrally. Similarly, if the anulus dilates, the bases of the leaflets are pulled outward and cause valve incompetence.

\section{Patients and methods}

From November 1990 to March 1996, 81 patients underwent aortic valve replacement (AVR) with a pulmonary autograft. There were 50 men and 31 women whose mean age was 32 years, range 10 to 53 years. Table I shows selected clinical, echocardiographic, and pathologic data on these patients. At the time of the operation, only one patient was in atrial fibrillation. Eleven patients had had previous aortic valve operations. Six patients had remote and one had active infective endocarditis. Doppler echocardiography was performed in all patients before, during, and after the operation. Coronary angiography was performed in 22 patients and none had significant coronary artery disease.

Operations were performed with the use of normothermic cardiopulmonary bypass, and myocardial protection was provided by continuous antegrade cold blood cardioplegic solution delivered directly into the coronary arteries. The ascending aorta was opened through a transverse incision a few millimeters above its sinotubular junction and the aortic valve was excised. The pulmonary artery was transected just before its bifurcation and the valve was inspected. If the valve was normal, the pulmonary root was circumferentially dissected and excised. Next, a cryopreserved pulmonary root homograft was used to reconstruct the right ventricular outflow tract.

The sinotubular junction of the pulmonary root was 


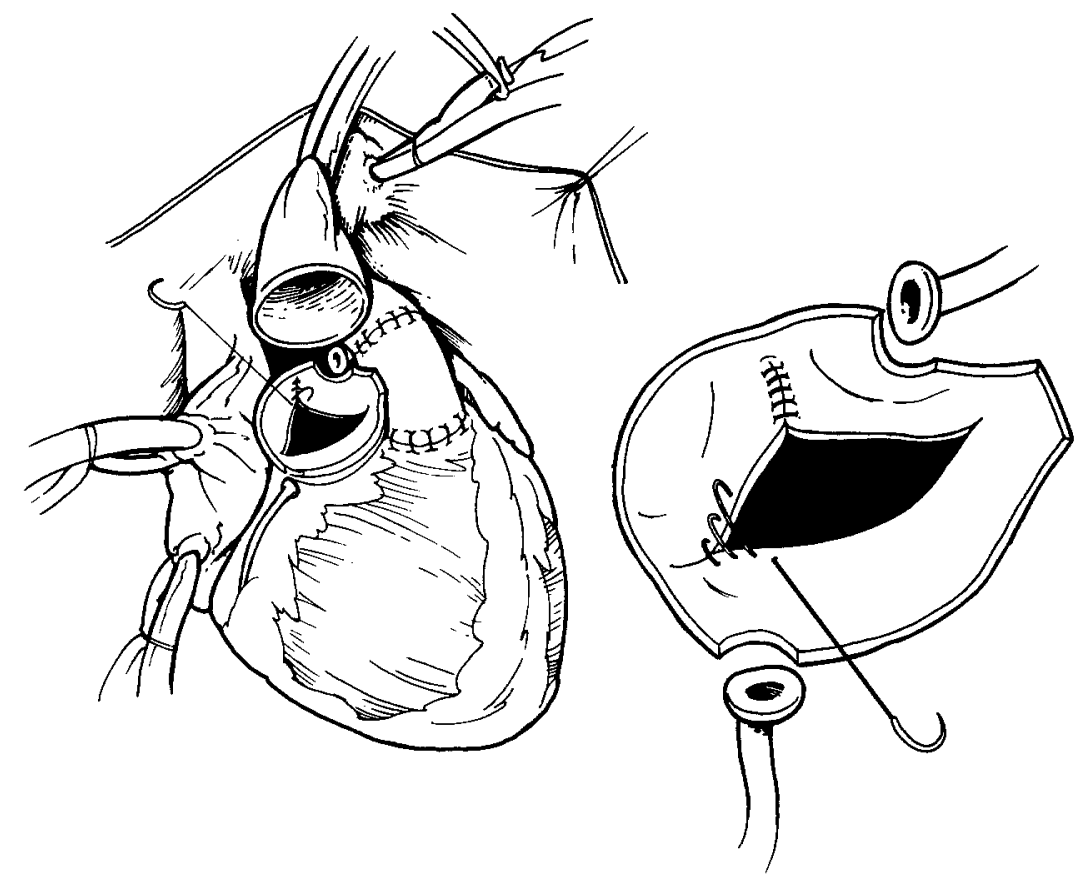

Fig. 2. Reduction of the aortic anulus by plication of the fibrous tissue beneath the commissures of the noncoronary aortic sinus.

carefully measured with metric sizers and the pulmonary anulus was assumed to be $10 \%$ larger than the diameter of the sinotubular junction. Overdistension of the pulmonary artery was avoided. The diameters of the aortic root were also measured. If the diameters of the anuli and sinotubular junctions were similar in both valves, the pulmonary autograft was implanted either in the subcoronary position in the aortic root or as a complete root replacement with reimplantation of the coronary arteries. However, if the diameter of the aortic anulus was larger than the diameter of the pulmonary anulus by more than $2 \mathrm{~mm}$, the aortic anulus was reduced by plicating the fibrous tissue underneath one or both commissures of the noncoronary aortic sinus, as illustrated in Fig. 2. If this maneuver was inadequate to reduce the diameter of the aortic anulus to that of the pulmonary anulus, an aortic annuloplasty was also performed. ${ }^{11}$ This was done by passing multiple mattress sutures of 4-0 polyester from the inside to the outside of the fibrous portion of the left ventricular outflow tract through a single horizontal plane just below the aortic anulus, and then through a strip of Dacron fabric placed outside the aortic root as shown in Fig. 3. These mattress sutures extended from the membranous interventricular septum to the lateral fibrous trigone underneath the left aortic sinus. The length of the strip of Dacron was determined by multiplying $0.6 \pi$ by the desired diameter of the aortic anulus $(0.6$ represents the proportion of the aortic anulus that is attached to fibrous tissue). After all sutures were tied, the diameter of the aortic anulus was measured again.
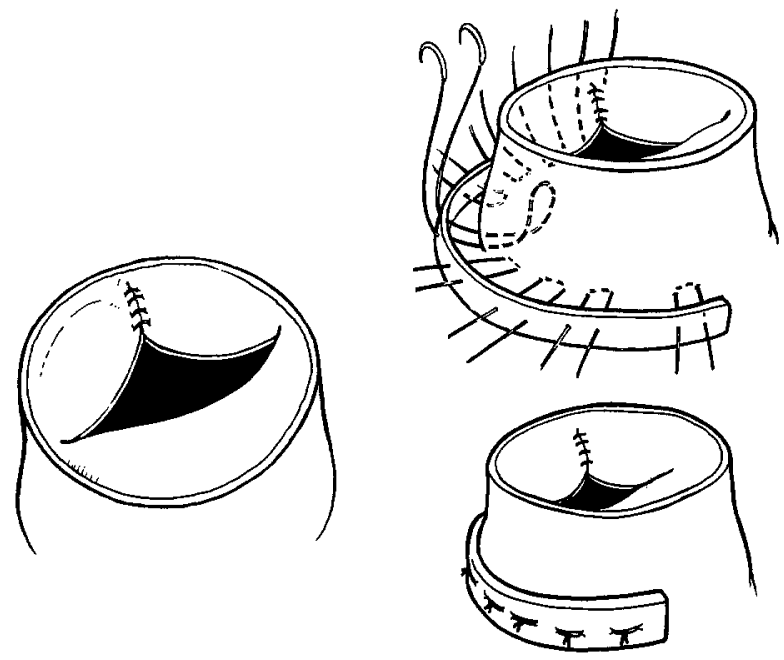

Fig. 3. Aortic annuloplasty with a strip of Dacron fabric. The annuloplasty in performed in addition to the plication of the subcommissural space.

Whenever the aortic root was larger than the pulmonary root, the pulmonary autograft was implanted as a free-standing root, or if the position of the coronary artery orifices matched that of the sinuses of the pulmonary autograft, a root inclusion technique was used. 

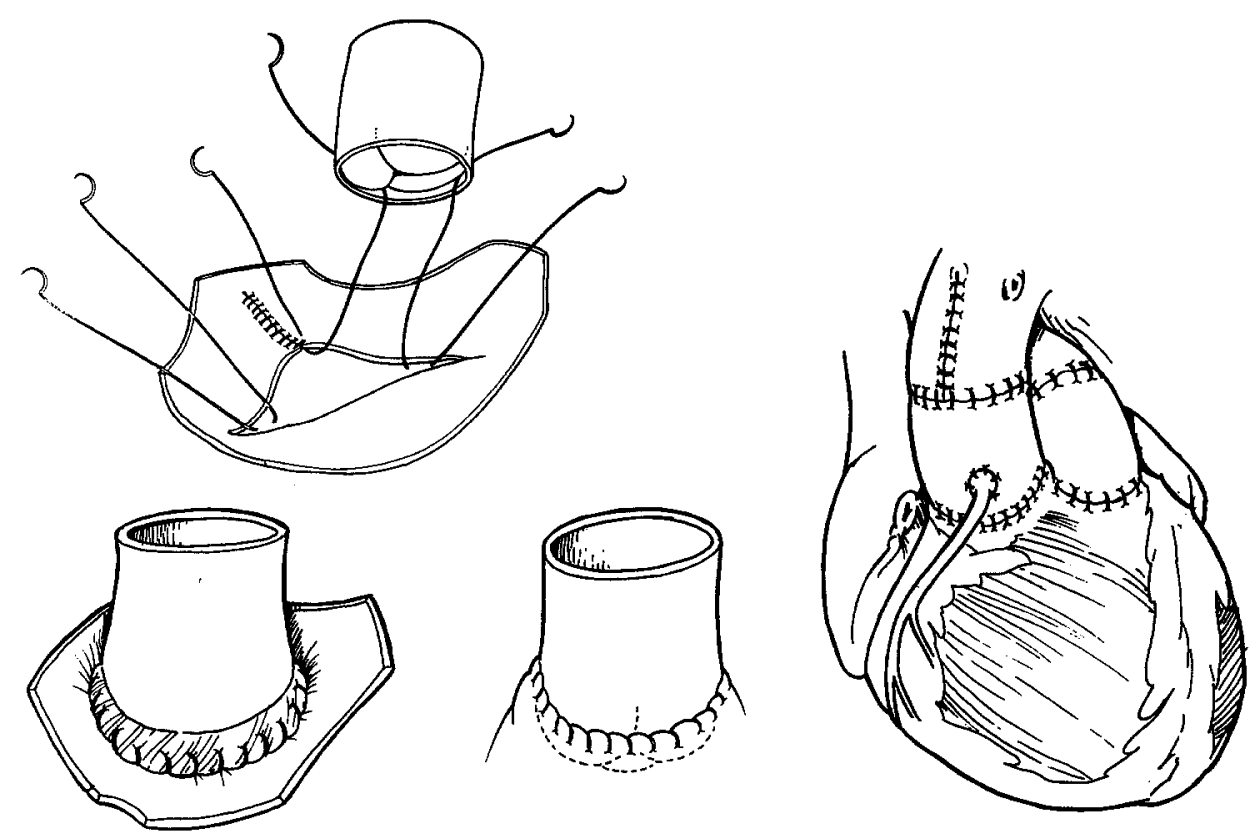

Fig. 4. Root replacement with pulmonary autograft. The aortic anulus was reduced in diameter. The remnants of the aortic sinuses were used to reinforce the anastomosis between the autograft and aortic anulus. The sinotubular junction and ascending aorta were reduced in diameter.

Table I. Operative data

\begin{tabular}{lc}
\hline Diameters (mm) & $27.1 \pm 3.9(19$ to 35$)$ \\
Aortic anulus & $24.0 \pm 2.1(19$ to 27$)$ \\
Pulmonary anulus & $26.8 \pm 3.7(20$ to 41$)$ \\
Aortic sinotubular junction & $21.5 \pm 2.0(17$ to 24$)$ \\
Pulmonary sinotubular junction & \\
Autograft implantation technique & 58 \\
Freehand valve & 21 \\
Complete root replacement & \\
Root inclusion & \\
Pulmonary valve replacement & 1 \\
Aortic homograft & 23 \\
$\quad$ Number of patients & \\
$\quad$ Diameter (mm) & 80 \\
Pulmonary homograft & $26.7 \pm 2.0(23$ to 30$)$ \\
$\quad$ Number of patients & \\
$\quad$ Diameter (mm) & 2 \\
Additional procedures & 1 \\
Resection of subaortic membrane & 1 \\
Closure of ventricular septal defect & 1 \\
Replacement of ascending aorta & $121 \pm 14$ (96 to 165) \\
Septal myectomy & \\
Coronary artery bypass & \\
Cardiopulmonary bypass time (min) & $140 \pm 26(110$ to 310$)$ \\
Aortic crossclamp time (min) & \\
\hline Values are expressed as mean \pm standard deviation; ranges are shown in \\
parenthesis.
\end{tabular}

The pulmonary autograft was secured to the left ventricular outflow tract just below the aortic anulus with multiple simple interrupted sutures of 4-0 polyester placed along a single horizontal plane. To facilitate an even distribution of the sutures, the muscle underneath was marked each of the three commissures of the pulmonary autograft with a fine suture, and the aortic anulus was also marked with three sutures placed at 120 degrees from each other with specifically designed metric sizers. In most patients who had complete root replacement, the anastomosis between the pulmonary autograft and the aortic root was covered with the remnants of the aortic sinuses by suturing it to the adventitia of the autograft with a continuous 5-0 polypropylene suture, as shown in Fig. 4. Probably the most functional orientation for the pulmonary autograft in the aortic root is to have its left sinus toward the left sinus of the aortic root.

If the sinotubular junction of the aorta was larger than the sinotubular junction of the pulmonary root by more than $2 \mathrm{~mm}$ in diameter, the ascending aorta was plicated to reduce its diameter to that of the pulmonary artery, as illustrated in Fig. 4.

Intraoperative measurements of the aortic and pulmonary roots were made in 77 patients. Reduction in the diameters of both the aortic anulus and the sinotubular junction was performed in 27 patients, reduction of the aortic anulus alone in 12 , and of the sinotubular junction alone in 10 . All patients who had bicuspid aortic valve and aortic insufficiency required plication of the aortic anulus. Table II summarizes the operative data. Patients had Doppler color echocardiographic studies during the operation, before hospital discharge, 2 to 6 months after the operation, and annually thereafter. Aortic insufficiency was quantitated by Doppler color flow mapping. ${ }^{13}$ Right ventricular function was qualitatively assessed, and left ventricular function was measured by circumferential shortening. 


\section{Results}

There was one operative death. This patient died suddenly on the fourth postoperative day after an uneventful operation and without electrocardiographic evidence of perioperative myocardial infarction. However, autopsy showed an extensive acute anterior wall myocardial infarction with normal coronary arteries.

One of the four patients who did not have intraoperative measurements of the semilunar valves had mild aortic insufficiency at the end of the operation, but it progressed to moderate insufficiency within 2 weeks. Echocardiography indicated that the aortic anulus dilated from $25 \mathrm{~mm}$ at the end of the operation to $39 \mathrm{~mm}$ by the end of the second postoperative week. Preoperatively, this patient had a left ventricular ejection fraction of $30 \%$, and it was deemed that his ventricular function might not improve with moderate aortic insufficiency. Reoperation was undertaken, but the pulmonary autograft could not be repaired and it was successfully replaced with an aortic valve homograft.

One patient could not be weaned from cardiopulmonary bypass. Because there were multiple visible atherosclerotic plaques in the left anterior descending and right coronary arteries (this patient had not had coronary angiography), both arteries were bypassed with saphenous vein grafts. This patient did well. In another patient with massive left ventricular hypertrophy and aortic stenosis, dynamic obstruction of the left ventricular outflow tract developed because of systolic anterior motion of the mitral valve. The patient was treated with septal myectomy. He had low cardiac output syndrome for a few days but also did well.

Other early postoperative complications included perioperative myocardial infarction in two patients (one septal and one inferior), transient cerebral ischemic attacks in two patients, postoperative bleeding necessitating reexploration of the mediastinum in one patient, atrial fibrillation in eleven, and transient postoperative jaundice with a rise in liver enzyme levels in one patient.

Patients have been followed up from 2 to 64 months (mean 15). Two patients required reoperation: one because of a false aneurysm between the pulmonary autograft and mitral valve, which was successfully repaired with preservation of the pulmonary autograft, and one because of stenosis of the homograft. This patient was the only one who had the pulmonary valve replaced with an aortic valve homograft. The homograft became stenotic after 3 years and was treated with a stent, but it became
Table III. Postoperative aortic insufficiency

\begin{tabular}{lccc}
\hline & $\begin{array}{c}1 \text { week } \\
\text { (81 patients })\end{array}$ & $\begin{array}{c}2-6 \text { mo } \\
(79 \text { patients })\end{array}$ & $\begin{array}{c}1-4 \mathrm{yr}^{*} \\
(58 \text { patients })\end{array}$ \\
\hline Aortic insufficiency & & & \\
None & 12 & 9 & 10 \\
Trace & 67 & 62 & 41 \\
Mild & 1 & 8 & 7 \\
Moderate & $1 \dagger$ & 0 & 0
\end{tabular}

*Most recent study.

$\nmid$ This patient underwent aortic root rereplacement.

stenotic again and was successfully replaced with a pulmonary homograft 1 year later. During the operation, the restenosis was found to be due to multiple layers of thrombi all along the stent. The leaflets were grossly normal.

At the most recent follow-up, 79 patients were free of symptoms of cardiac disease. None had had late thromboembolic or infective complications. All patients were in sinus rhythm. The patient in whom systolic anterior motion of the mitral valve developed no longer had obstruction of the left ventricular outflow tract, but he was receiving $\beta$-adrenergic blockers for systemic hypertension. No patient had a diastolic murmur of aortic insufficiency.

The function of both semilunar valves and ventricles has been assessed periodically by Doppler echocardiography. Table III summarizes the findings related to competence of the pulmonary autograft. At the latest study almost $90 \%$ of the patients have trace or no aortic insufficiency, and the other patients have mild aortic insufficiency. The mean peak systolic gradient across the aortic valve was $8 \pm 5$ $\mathrm{mm} \mathrm{Hg}$, range 0 to $16 \mathrm{~mm} \mathrm{Hg}$. Postoperative left ventricular function was normal in 75 patients and mildly impaired in four. No patient had more than mild pulmonary insufficiency, and the mean peak systolic gradient across the pulmonary homograft was $13 \pm 10 \mathrm{~mm} \mathrm{Hg}$, range 0 to 28 . However, of 57 patients who had the pulmonary homograft for more than 1 year, nine patients $(16 \%)$ had peak systolic gradients between 20 and $28 \mathrm{~mm} \mathrm{Hg}$ across the pulmonary valve. There was no correlation between the peak systolic gradient and the diameter of the pulmonary valve homograft implanted, but only seven patients had homografts smaller than 25 $\mathrm{mm}$ in diameter. Postoperative right ventricular function was normal in 78 patients and mildly impaired in one.

The actuarial survival as estimated by the KaplanMeier method was $98 \% \pm 1 \%$ at 3 years. 


\section{Discussion}

There has been renewed interest in the pulmonary autograft for AVR in children and $; \cdots$ nng adults because of its potential for growth and because it may cure the patient's aortic valve disease permanently. ${ }^{4,5}{ }^{14-16}$ However, technical errors during the dissection and implantation of the pulmonary autograft, geometric mismatch between the paticnt's two semilunar valves, and late endocarditis may cause the pulmonary autograft to fail. ${ }^{2-7}$ On the basis of our experience with aortic valve repair in patients with aortic root aneurysms, we have learned that the morphometric relationships between the leaflets and the aortic root are very important for valve function. ${ }^{11,12}$ In this present study we pointed out that intraoperative measurements of the pulmonary and aortic roots, and surgical adjustment of the aortic root when it is larger than the pulmonary root, may be important to prevent postoperative aortic insufficiency after AVR with a pulmonary autograft. In almost two thirds of our patients the aortic root required some reduction in diameter to match the autograft. In no patient was the pulmonary autograft larger than the aortic root. This approach was used in 77 patients without failures of the autograft. The only pulmonary autograft failure occurred in a patient in whom no measurements were taken.

Congenital bicuspid aortic valve disease is the most common cause of aortic valve disease in young adults. Dilatation of the aortic root is a common finding in patients with congenital bicuspid aortic valve. ${ }^{17}$ This abnormality was present in all our patients with congenital bicuspid aortic valve. The pulmonary root is usually normal in these patients, but because both semilunar valves have the same embryologic origin, one may hypothesize that the pulmonary root may dilate when transferred to the aortic position. In addition, there is evidence that an aortopathy may be present or may develop in patients with a bicuspid aortic valve and that such patients have an increased risk of type A aortic dissection. ${ }^{18}$ Although these are valid concerns, we have not observed progressive dilatation of the pulmonary roots in our patients who had bicuspid aortic valve. However, our follow-up is very short. Obviously, this operation should not be performed in patients with the Marfan syndrome or in those with aortic root aneurysms.

Dilatation of the pulmonary autograft causes aortic insufficiency. ${ }^{6,7}$ Moritz and associates ${ }^{7}$ reduced the diameter of the aortic anulus and wrapped the autograft with an absorbable mesh in a few patients who had the Ross procedure as an attempt to prevent postoperative aortic insufficiency. Pacifico and colleagues ${ }^{6}$ described an operative technique whereby the entire pulmonary autograft was wrapped with glutaraldehyde-fixed bovine pericardium to prevent dilatation. Because there is echocardiographic evidence that the sinuses of the pulmonary autograft do not dilate, ${ }^{15,16,19}$ there is no need to wrap the entire graft with a foreign material. We believe that the important factor in preventing aortic insufficiency is to adjust the diameters of the aortic anulus and of the sinotubular junction to those diameters of the pulmonary autograft when they are not similar. Reduction of the aortic anulus to prevent aortic insufficiency during AVR with a pulmonary autograft was recently described by Elkins, Knott-Craig, and Howell, ${ }^{20}$ in a group of 20 patients, and 18 of them had only a trace or no aortic insufficiency in late echocardiographic studies. These investigators reduced the diameter of the aortic anulus with two purse-string sutures around the left ventricular outflow tract. In addition, a circumferential strip of Teflon felt was used to buttress the suture line between the left ventricular outflow tract and the pulmonary autograft. ${ }^{20}$

The aortic leaflets are thicker than the pulmonary leaflets, ${ }^{21}$ likely as a result of their function. It is conceivable that when the pulmonary autograft is implanted in the aortic position, the fibroblasts present in the leaflets of the pulmonary valve produce more collagen to strengthen them. Interestingly, a study by Gaudino and Goffin ${ }^{22}$ on AVR with pulmonary homografts showed that the durability of the homograft depended on the pulmonary artery pressure of the donor. Those valves that came from donors with pulmonary hypertension were more durable than those from donors with normal pulmonary artery pressure. ${ }^{22}$ We have observed that the cellularity of the semilunar valves decreases with age. Thus it is possible that the pulmonary valve of a patient in the sixth decade of life may not have the same ability to produce collagen and adjust itself to the aortic pressures as does the pulmonary valve of a younger patient. These observations suggest that AVR with a pulmonary autograft may not be appropriate for elderly patients.

Although AVR with a pulmonary autograft may cure the aortic valve disease, it creates pulmonary valve disease. The clinical experience with reconstruction of the right ventricular outflow tract with aortic and pulmonary homografts suggests that 
these grafts will eventually fail. ${ }^{23,24}$ Pulmonary homografts are more durable than are aortic homografts when used for reconstruction of the right ventricular outflow tract in patients with congenital heart disease. ${ }^{23,24}$ The freedom from failure of the pulmonary homograft in children older than 4 years was $95 \%$ at 5 years in a report by Bando and coworkers. ${ }^{24}$

AVR with a pulmonary autograft is an operation whereby a normal pulmonary valve is used to replace an abnormal aortic valve. These two semilunar valves often have different morphometric features that must be taken into account during the execution of the operation. We firmly believe that intraoperative measurements of both semilunar valves and adjustment of the aortic root when necessary are important factors to prevent postoperative aortic insufficiency. However, there are numerous unresolved issues regarding the long-term results of this procedure, and we agree with Dr. Hurvitz's statement that this "is a complex procedure requiring considerable expertise" to be performed, and it "is still in an evaluating stage." 25

\section{REFERENCES}

1. Ross DN. Replacement of the aortic and mitral valves with a pulmonary autograft. Lancet 1967;2:956-8.

2. Sommerville J, Saravalli O, Ross DN, Stone S. Long-term results of pulmonary autograft for aortic valve replacement. Br Heart J 1979;42:533-40.

3. Matsuki O, Okita Y, Almeida RS, et al. Two decades' experience with aortic valve replacement with pulmonary autograft. J Thorac Cardiovasc Surg 1988;95:705-11.

4. Gerosa G, McKay R, Ross DN. Replacement of the aortic valve or root with a pulmonary autograft in children. Ann Thorac Surg 1991;51:424-9.

5. Elkins RC, Knott-Craig CJ, Razook JD, Ward KE, Overholt ED, Lane MM. Pulmonary autograft replacement of the aortic valve in the potential parent. J Card Surg 1994; 9(Suppl):198-203.

6. Pacifico AD, Kirklin JK, McGiffin DC, Matter GJ, Nanda NC, Diethelm AG. The Ross operation-early echocardiographic comparison of different operative techniques. J Heart Valve Dis 1994;3:365-70.

7. Moritz A, Domanig E, Marx M, et al. Pulmonary autograft valve replacement in the dilated and asymmetric aortic root. Eur J Cardiothorac Surg 1993; 7:405-8.

8. Sands MP, Rittenhouse EA, Mohri H, Merendino KA. An anatomical comparison of human, pig, calf, and sheep aortic valves. Ann Thorac Surg 1969;8:407-14.

9. Silver MA, Roberts WC. Detailed anatomy of the normally functioning aortic valve in hearts of normal and increased weight. Am J Cardiol 1985;55:454-61.

10. Kunzelman KS, Grande KJ, David TE, Cochran RP, Verrier ED. Aortic root and valve relationship: impact on surgical repair. J Thorac Cardiovasc Surg 1994;107:162-70.

11. David TE, Feindel CM, Bos J. Repair of the aortic valve in patients with aortic insufficiency and aortic root aneurysm. J Thorac Cardiovase Surg 1995;109:345-52.

12. David TE. An anatomic and physiologic approach to acquired heart disease. Eur J Cardiothorac Surg 1995;9:175-80.

13. Weyman AE, Griffin BP. Left ventricular outflow tract: the aortic valve, aorta, and subvalvular outflow tract. In: Weyman AE, editor. Principles and practice of echocardiography. Philadelphia: Lea \& Febiger, 1994:498-574.

14. Ross D, Jackson M, Davies J. The pulmonary autograft-a permanent aortic valve. Eur J Cardiovasc-thorac Surg 1992; 6:113-6.

15. Elkins RC, Knott-Craig CJ, Ward KE, McCue C, Lane MM. Pulmonary autograft in children: realized growth potential. Ann Thorac Surg 1994;57:1387-93.

16. Kouchoukos NT, Davilla-Roman VG, Spray TL, Murphy SF, Perrillo JB. Replacement of the aortic root with a pulmonary autograft in children and young adults with aortic valve disease. N Engl J Med 1994;330:1-6.

17. Olson LJ, Subramanian R, Edwards WD. Surgical pathology of pure aortic insufficiency: a study of 225 cases. Mayo Clin Proc 1984;59:835-41.

18. Edwards WD, Lelaf DS, Edwards JE. Dissecting aortic aneurysm associated with congenital bicuspid aortic valve. Circulation 1978;57:1022-5.

19. Sievers HH, Leyh R, Loose R, Guha M, Petry A, Bernhard A. Time course of dimensions and function of the autologous pulmonary root in the aortic position. J Thorac Cardiovasc Surg 1993;105:775-80.

20. Elkins RC, Knott-Craig CJ, Howell CE. Pulmonary autografts in patients with aortic annulus dilatation. Ann Thorac Surg. In press.

21. David H, Boughner DR, Vesely I, Gerosa G. The pulmonary valve. Is it mechanically suitable for use as an aortic valve? ASAIO J 1994;40:206-12.

22. Gaudino M, Goffin Y. Are pulmonary homografts subjective to pulmonary hypertension more appropriate for left ventricular outflow tract than normal pulmonary homografts? Results of echocardiography in a multicenter study. Eur J Cardiovasc-thorac Surg. In press.

23. Albert JD, Bishop DA, Fullerton DA, Campbell DN, Clarke DR. Conduit reconstruction of the right ventricular outflow tract lessons learned in a twelve-year experience. J Thorac Cardiovasc Surg 1993;106:228-35.

24. Bando K, Danielson GK, Schaff HV, Mair DD, Julsrud PR, Puga FJ. Outcome of pulmonary and aortic homografts for right ventricular outflow tract reconstruction. J Thorac Cardiovase Surg 1995;109:509-18.

25. Hurvitz RJ. The Ross procedure: to do or not to do [letter] Ann Thorac Surg 1994;58:1565-6.

\section{Discussion}

Dr. Nicholas T. Kouchoukos (St. Louis, Mo.). Dr. David and his associates have focused on what is emerging as the major complication of the Ross procedure, namely, the postoperative development and progression of aortic regurgitation and the need for reoperation for this complication. Dr. David has described several techniques for reducing the mismatch between the diameters of the autograft and the aortic root at the level of the anulus and at the sinotubular junction when this mismatch is more than 2 or $3 \mathrm{~mm}$. These modifications have resulted in a 
low incidence of more than mild aortic regurgitation during the follow-up, which averages 15 months.

In a series of 80 patients who have been operated on by my colleagues and me at the Washington University Medical Center, in whom only root replacement was used as the technique of insertion, we have used several of the techniques that Dr. David has described to correct for mismatch. In addition, we have used a strip of Teflon felt or pericardium to buttress the annular suture line in adults or older children, in whom growth of the autograft is not a concern. To correct the mismatch at the sinotubular junction, we have buttressed the suture line with a strip of felt or resected the dilated aorta and replaced it with a Dacron tube graft that is equal in diameter to the pulmonary artery. The latter modification was performed in seven patients. In the subgroup of 22 patients who were followed up for a minimum of 3 years and for up to 7 years (a mean of 53 months), the mean diameter of the aortic anulus measured echocardiographically was unchanged. The mean diameter at the sinotubular ridge increased 1.5 $\mathrm{mm}$, from 25.5 to $27.0 \mathrm{~mm}$. Ártic regurgitation progressed from the mild to the moderate range in only one of the 22 patients, and this was not associated with any substantial increase in the annulat or sinotubular diameter of the autograft. Thus the modifications described by Dr. David, when used alone or in combination with those reported by others, including ourselves, Dr. Ross, and Dr. Elkins, will likely decrease the incidence of substantial aortic regurgitation and reoperation and may even expand the indications for the Ross procedure.

I have several questions. You used three techniques for implantation of the autograft. Could you give us your current indications for use of the subcoronary and the inclusion cylinder techniques? Is there a role for the Ross operation and your tailoring techniques in patients with annuloaortic ectasia who do not have Marfan's syndrome?

In contrast to your experience, we have encountered three female patients with congenital aortic stenosis and hypoplasia of the aortic root in whom the diameter of the aortic anulus was smaller than the diameter of the pulmonary autograft. Is there a role for tailoring of the aortic root in this setting?

Dr. David. Thank you, Dr. Kouchoukos. The autograft was implanted in the subcoronary position in only two patients, and in those two patients the anatomy of the aortic root was identical to the anatomy of the pulmonary root. In other words, the aortic anulus measured the same as the pulmonary anulus and the sinotubular junction was the same as the pulmonary. When both are identical, I find the subcoronary position the easiest and fastest technique. It can be done within 40 to 50 minutes, as opposed to 2 hours for most cases of root replacement. The inclusion cylinder is used in patients who have a rather dilated aortic root with the autograft being much smaller than the aortic root. Complete root replacement was used in the remaining patients.

In our experience, patients who have a bicuspid aortic valve and aortic insufficiency always have annuloaortic ectasia; the aortic anulus is not normal, and these are the patients who had plication of the aortic anulus and of the sinotubular junction. I do not think annuloaortic ectasia in patients with a bicuspid aortic valve is a contraindication for the Ross procedure. In patients in whom the bicuspid aortic valve becomes stenotic, the aortic anulus is not as ectatic as in those who have aortic insufficiency. We have never done this operation on patients with Marfan's disease because I am concerned that if the pulmonary and the aortic roots have the same embryologic origins, dilation may occur once the pulmonary root is transferred to the aortic position.

I have not yet encountered a patient with a hypoplastic aortic anulus that is smaller than the size of the autograft. However, aortic anulus enlargement procedures combined with the Ross procedure have been reported.

Dr. James H. Oury (Missoula, Mont.). I would add a word of caution that we not make what is already a complex operation more complex. I think the problem is technical and not anatomic. Thus I would question your second conclusion only from that standpoint. In the registry, which now numbers more than 2000 patients, there is no relation between the size of the pulmonary anulus and the aortic anulus in postoperative aortic insufficiency. Again, this implicates technical factors related to its insertion. A proposal would be that we adopt a safe technique similar to the technique of the interrupted proximal suture line with some form of external support, and you have demonstrated this in a portion of your paicents. We have used this in 65 cases over the past 5 years. Our incidence of postoperative aortic insufficiency is very similar to yours in this match-up, and we have had no deaths in this series. Thus I think an external form of support, either Dacron fabric or pericardium, is to the patient's advantage and in some cases has been used. This does achieve a staged circumferential annuloplasty and has the side benefit that the proximal suture line is perfectly hemostatic.

The question, Dr. David, is this: If this is valuable in those cases that you have identified with mismatch, why shouldn't it be used in at least every adult patient in whom the Ross procedure is done as a mechanism for providing a fixed form of external support?

Dr. David. I think we are accomplishing the same thing. Whether you put a piece of Tefion felt along the anastomosis or adjust the aorta before putting the autograft in is largely a personal preference.

I work in a referral center for patients with active endocarditis. I have operated on at least three patients who had aortic root replacement, one with a pulmonary autograft and two with aortic homografts, in whom the infection was in the Teflon felt used to buttress the anastomosis between the graft and aortic anulus. When I reoperated on these patients I found that the Teflon felt had migrated and become part of the outflow tract and was the nidus of the infection. I participated in a teleconference last month with Dr. Elkins, who has performed this operation, and he brought this issue up for discussion. $\mathrm{He}$ decreases the aortic anulus with double purse-string sutures all around the outflow tract first, and then he places Teflon felt outside the aorta, which is another way to accomplish the same thing. The message I am trying to convey is that if there is disparity in the sizes of the aortic and pulmonary anuli, the pulmonary autograft will dilate with time. The conal muscle disappears entirely and becomes replaced by scar tissue. 
Dr. Gosta Pettersson (Copenhagen, Denmark). In Copenhagen we have performed 81 Ross operations, and sizing and geometric considerations have been an increasingly important issue, as they obviously have been to you. Like you, we base the operation sizewise on the prebypass size of the pulmonary artery sinotubular junction. In the last two thirds of our series in which we have performed aortic annular and sinotubular junction reduction reconstructions when necessary, strictly according to the principles that you have outlined, we have not seen more than one-plus-one autograft insufficiency. We agree that a less than perfect result with an operation for which we have safer alternatives is unacceptable.

Have you set any limits beyond which you would not do a Ross operation in relation to the size of the aortic anulus, to the size of the ascending aorta, or to the underlying aortic root disease? Do you have any thoughts about relative importance of perfect annular sizing versus a perfect sizing of the sinotubular junction? Finally, I agree with your comments about external support and the risk of endocarditis. We have included a number of those.

Dr. David. I have never done the Ross procedure in someone with an aortic root aneurysm. Whether they have Marfan's syndrome or not, if they have an aortic root aneurysm, and we call an aneurysm anything more than 45 $\mathrm{mm}$ or $50 \mathrm{~mm}$, we do not do this operation. Discrepancy in the diameter of the sinotubular junction and the aortic anulus varies from patient to patient. The more the leaflets coapt, the more forgiving the discrepancy in diameter can be. As the sinotubular junction dilates, the leaflets are pulled outward, but before regurgitation occurs, the coaptation surface decreases. The more the anulus dilates, the closer it drags the coapting margin to the outflow tract of the left ventricle. Aortic valve repair has taught us that neither the diameter of the aortic anulus nor sinotubular junction should exceed the length of the free margin of the leaflets.

Dr. Robert K. Salley (Lexington, Ky.). I rise to echo some of Dr. David's comments regarding a similar experience that we have had in our 50 consecutive Ross procedures. We have also had a concern regarding a size mismatch between the pulmonary autograft and the left ventricular outflow tract, and we have used a 26 or $28 \mathrm{~mm}$ Dacron graft ring incorporated into the proximal suture line of the free root replacement. This ring buttresses and downsizes the left ventricular outflow tract. In this series, five patients have undergone that technique, and we have seen no progression of any insufficiency in any of our patients. We believe this is an important component of the procedure.

My first question concerns your plication technique and whether you have seen any mitral valve difficulties related to the possibility of a malalignment of the intertrigonal area of the mitral valve leading to new mitral valve insufficiency.

We have measured pulmonary anulus size echocardiographically in the dynamic state to allow us to measure that anulus in situ rather than after it has been explanted. We have used that number to determine the size of the left ventricular outflow tract to which we would downsize. Have you made use of echocardiographic data in your pulmonary valve sizing?

Dr. David. I do not think plication of the subcommissural area interferes with the mitral valve. The first centimeter or two of the mitral valve that is attached to the aortic anulus does not move much during the cardiac cycle. If you look at the anterior leaflet of the mitral valve by echocardiography, only the distal half moves during the cardiac cycle. The fibrous curtain between the aortic and mitral valves is a stationary fibrous structure. Plication of the subaortic commissural spaces should not affect the function of the mitral valve.

We also measure the pulmonary and aortic anuli by echocardiography, but the problem is that the pulmonary anulus is distensible. Its diameter varies depending on the volume of the right ventricle. As the right ventricle distends, so does the pulmonary anulus. We use the sinotubular junction of the pulmonary valve both by echocardiographic and intraoperative measurement to determine the diameter of the pulmonary anulus. 